\title{
External supports improve knee performance in anterior cruciate ligament reconstructed individuals with higher kinesiophobia levels
}

\author{
Gulcan Harput a,*, Burak Ulusoy ${ }^{\mathrm{a}}$, Hamza Ozer ${ }^{\mathrm{b}}$, Gul Baltaci ${ }^{\mathrm{c}}$, Jim Richards ${ }^{\mathrm{d}}$ \\ a Hacettepe University, Faculty of Health Sciences, Department of Physiotherapy and Rehabilitation, Ankara, Turkey \\ b Gazi University, Faculty of Medicine, Department of Orthopaedic and Traumatology, Ankara, Turkey \\ c Private Ankara Guven Hospital, Ankara, Turkey \\ d University of Central Lancashire, Allied Health Research Unit, Preston, UK
}

\section{A R T I C L E I N F O}

\section{Article history:}

Received 19 October 2015

Received in revised form 27 February 2016

Accepted 10 May 2016

\section{Keywords:}

$\mathrm{ACL}$

Kinesiophobia

Brace

Kinesiotaping

\begin{abstract}
A B S T R A C T
Background: The objectives of this study were to investigate the effects of knee brace (KB) and kinesiotaping (KT) on functional performance and self-reported function in individuals six months post-ACLR who desired to return to their pre-injury activity levels but felt unable to do so due to kinesiophobia.

Methods: This was a cross-sectional study involving 30 individuals six months post-ACLR with Tampa Kinesiophobia Scores > 37. Individuals were tested under three conditions: no intervention, KB and KT in a randomized order. Isokinetic concentric quadriceps and hamstring strength tests, one leg hop test, star excursion balance test and global rating scale were assessed under the three conditions.

Results: The involved side showed that KT and KB significantly increased the hop distance $(P=0.01, P=0.04)$ and improved balance $(P=0.01, P=0.04)$, respectively, but only $\mathrm{KB}$ was found to increase the quadriceps and hamstring peak torques compared to no intervention $(P<0.05)$. Individuals reported having better knee function with KB when compared to no intervention $(P<0.001)$ and KT $(P=0.03)$.

Conclusions: Both KB and KT have positive effects in individuals post-ACLR which may assist in reducing kinesiophobia when returning to their pre-injury activity levels, with the KB appearing to offer the participants better knee function compared to KT.
\end{abstract}

(C) 2016 Elsevier B.V. All rights reserved.

\section{Introduction}

Anterior cruciate ligament $(\mathrm{ACL})$ rupture is the most common knee injury in sports which often occurs during non-contact cutting, jumping and pivoting activities $[1,2]$. ACL rupture is often treated with ACL reconstruction (ACLR) depending on the patients' expectations about the treatment, pre-injury physical activity level and desire to return to sport (RTS) [3]. Although ACLR is performed to stabilize the knee joint to prevent further injuries, it does not guarantee that patients will return to their pre-injury activity levels $[4,5]$.

Physical, psychological and demographical factors are shown to influence the rate of RTS after ACL surgery [6]. Making RTS decisions following ACLR depends on a group of performance-based tests to detect side-toside asymmetries and patient-reported knee function measurements [7-9]. The readiness for RTS is often assessed by a patient's ability to achieve $85 \%$ or greater on the Limb Symmetry Index (LSI) [10-12]. However, a meta-analysis demonstrated that only $64 \%$ of patients returned to sports after ACLR, whereas approximately 85 to $90 \%$ achieved successful

\footnotetext{
* Corresponding author. Tel.: +90 3123052525186.

E-mail addresses: aktasgulcan@yahoo.com, gulcan.aktas@hacettepe.edu.tr (G. Harput).
}

outcomes in knee and patient-reported function assessments [4]. Therefore, psychological factors have been thought to cause the mismatch between postoperative knee function outcomes and rates of RTS [4,13-15]. Ardern et al. [13] demonstrated an association between psychological factors and RTS rate after ACL injury. Fear of re-injury (kinesiophobia) is one of the most challenging psychological factors after ACL injuries $[14,15]$ and up to $24 \%$ of ACLR patients were shown not to return to sport due to kinesiophobia [14]. Kinesiophobia levels can be objectively evaluated by Tampa Scale of Kinesiophobia (TSK-17). Although TSK scores generally decrease after ACLR, higher TSK scores still exist in RTS phases of ACLR rehabilitation and correlates to lower self-reported knee function $[10,16]$.

Previous studies have focused on the biomechanical effects of knee bracing after ACLR; however, knee braces (KBs) may also improve functional performance during tasks such as single limb balance $[17,18]$ and self-reported knee function in ACLR individuals [19]. Although the use of KBs after ACLR is still a debatable issue [20,21], ACLR individuals commonly use them in the RTS phase to improve their confidence in their affected knee [22]. It has been reported that $62.9 \%$ of surgeons recommended a brace for their patients when participating in sports after ACLR [23]. Although Goodstadt et al. [24] suggested that patients should discontinue to use bracing when they had 
passed RTS criteria as using knee bracing might become a hindrance to patients' performance.

Kinesiotaping (KT) applications have increased in recent years in orthopedic patients [25]. KT can be stretched up to $100 \%$ of its original length, although tension techniques can differ according to the application area [25]. There are several theories behind how KT could affect muscle activity and joint control $[25,26]$. KT could be stimulating the cutaneous mechanoreceptors and thus changing the recruitment of motor units [26]; KT may also stimulate the fascia and provide tension which could change the muscle activation [25]. As ACLR alters the sensory and motor components of the knee, KT application might be effective in enhancing neuromuscular control of the knee and providing functional support [27]. However, Oliveira et al. [27] found that KT had no immediate effect on enhancing balance and hop performance in ACLR individuals. As a result, there is currently limited evidence as to whether KT is effective for improving functional performance in ACLR individuals wishing to return to pre-injury activity levels.

This study aimed to investigate the effects of a drytex hinged KB and KT on functional performance and self-reported function in individuals six months after ACLR who desired to return to their pre-injury activity levels but felt unable to do so because of kinesiophobia. It was hypothesized that such external supports would increase the functional performance and self-reported function in individuals with higher levels of kinesiophobia.

\section{Methods}

\subsection{Study design}

We used a cross-sectional design with repeated measures in which functional performance and patient self-reported knee functions were tested with knee bracing, KT, and no intervention, in a randomized order.

\subsection{Participants}

Thirty ACLR patients (age: $25.1 \pm 7.8$ years, body mass index (BMI): $23.9 \pm 3.5 \mathrm{~kg} / \mathrm{m}^{2}$, Tegner Score: $6.2 \pm 1.3$ ) were included in this study. The ACL surgery was performed by a single orthopedic surgeon using a quadrupled semitendinosus-gracilis (single-bundle) autograft followed by an ACLR rehabilitation program. Inclusion criteria of the study were: (1) isolated ACL injuries; (2) unilateral arthroscopic ACLR; (3) age between 17 and 45 years; (4) pre-injury Tegner score $\geq 5$; (5) regular attendance, missing no more than three sessions of ACLR rehabilitation in the first three months after ACLR; (6) desire to RTS but could not due to fear of re-injury (TSK-17 score $\geq 37$ ) [28] at six months after ACLR.

We specified a pre-injury Tegner activity level of at least five to involve only physically active individuals in the study. Only the patients whose kinesiophobia levels were $\geq 37$ were included in this study in order to observe whether bracing and KT taping could help them achieve better functional outcomes and improve their confidence in the knee which had undergone ACLR. Informed consent was obtained from all individual participants included in the study, and the protocol for the study was approved by the University Institutional Review Board.

Individuals were tested under three conditions: with no intervention, with KB, and with KT in a randomized order with one week intervals between test conditions. The KB and KT were worn for $30 \mathrm{~min}$ before beginning the tests. The data were collected for concentric knee strength, hop distance, dynamic balance and Global Rating Scale (GRS) for evaluating self-reported knee function.

\subsection{ACLR rehabilitation program}

The early phases of the neuromuscular ACLR rehabilitation program started within the first week of surgery and the individuals were instructed to attend the program three days/week until 12 weeks after ACLR. The early postoperative phase of the rehabilitation emphasized limiting hemarthrosis and edema, obtaining full knee range of motion, achieving good quadriceps muscle control and contralateral limb strengthening. The progression of the rehabilitation program incorporated core, balance and strengthening exercises. The therapy sessions were individualized to the individuals' needs and the average session lasted approximately $1.5 \mathrm{~h}$. Every participant was instructed to visit the clinic for progressive neuromuscular training once per month when they finished the early phase of the rehabilitation program. The progressive neuromuscular training included plyometric, running and agility training. The tests were carried out at six months post-ACLR and all participants performed each training program before participating in this study.

\subsection{Test conditions}

\subsubsection{Knee brace}

A prophylactic KB (Drytex economy hinged knee, DJO Inc.; Figure 1), which had been found to be effective in enhancing the lower limb functional performance in healthy individuals previously [29], was chosen. This brace was designed for mild medial and lateral support of the knee during daily living activities and/or contact sports. It is constructed of nylon core and polyester lycra fabric with bilateral polycentric aluminum upright hinges with a total weight of less than $500 \mathrm{~g}$.

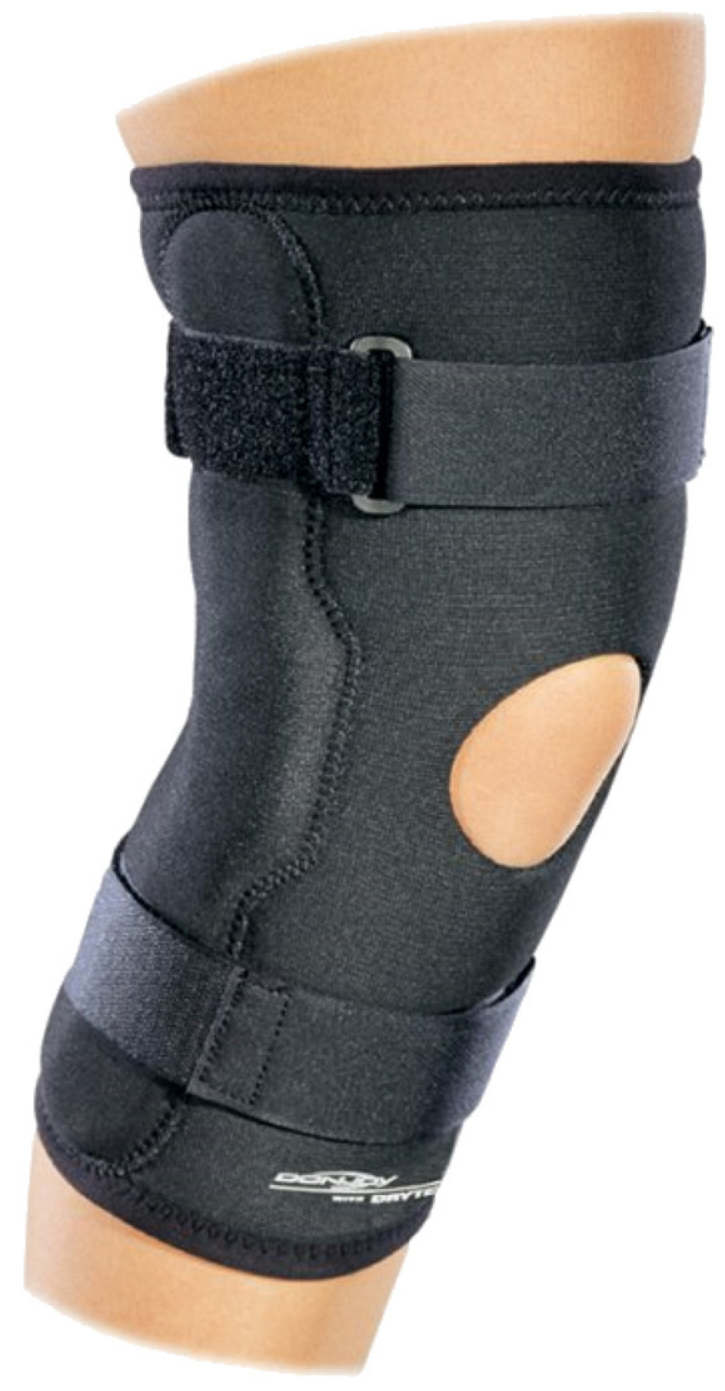

Figure 1. Prophylactic knee brace. 


\subsubsection{Kinesiotaping application}

KT was applied to the skin over rectus femoris using the muscle facilitation technique, with a mechanical correction for patella and ligament technique for patellar tendon [25]. The participants were instructed to lie in the supine position with their knee flexed at $90^{\circ}$. For the tape over the rectus femoris muscle, the base of the strip was applied $10 \mathrm{~cm}$ below the anterior superior iliac spine and fixed without tension along the line of action of the rectus femoris to the superior border of the patella. The distal end of the strip was cut into two and applied on the medial and lateral borders of the patella with $75 \%$ tension [30]. A second strip was applied over the patellar tendon with $100 \%$ tension with the knee in its most flexed position (Figure 2). The application of the tape was performed by the same clinician, who was experienced in the application of KT (GH).

\subsection{Testing overview}

The performance tests included knee strength, hop performance and dynamic balance.

\subsubsection{Knee strength}

Concentric quadriceps and hamstring torques were measured by isokinetic dynamometer (IsoMed®2000 D\&R GmbH, Germany). The participants were instructed to sit on the isokinetic dynamometer with their hips flexed at $90^{\circ}$. Stabilization straps were placed across the trunk, waist and the distal femur of the limb to minimize compensatory movement. The axis of the dynamometer was aligned to the lateral femoral epicondyle while the knee was flexed at $90^{\circ}$ and the dynamometer force arm was secured two centimeters above the lateral malleolus. The distance from the dynamometer force arm to the axis of the dynamometer was recorded for each individual to allow the peak torque to be calculated.

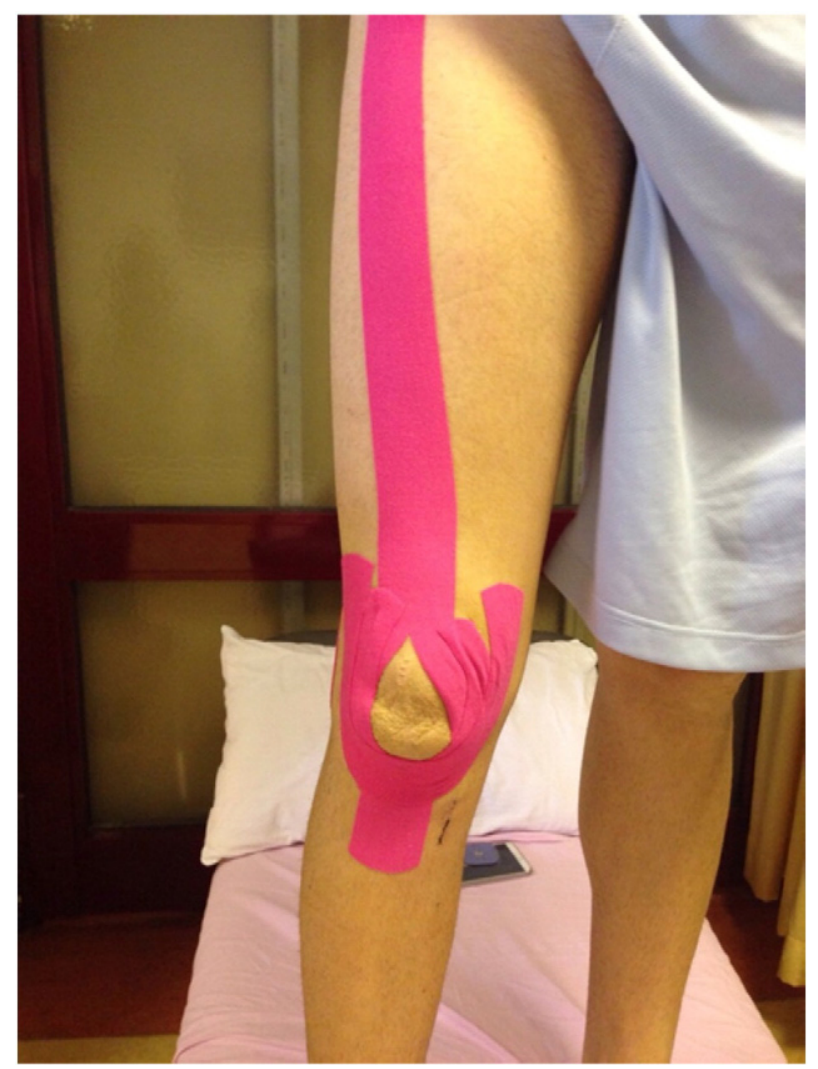

Figure 2. Kinesiotaping application.
Prior to muscle strength recordings, the participants were allowed three maximal concentric quadriceps and hamstring tests to familiarize themselves with the testing procedures and to warm-up. The participants then performed reciprocal maximal quadriceps and hamstring concentric contractions at angular velocities of $60^{\circ} / \mathrm{s}$ ( 5 repetitions) and $180^{\circ} / \mathrm{s}$ (10 repetitions) with a one minute rest interval between each set. Standard verbal instructions were given regarding the procedures. Quadriceps and hamstring peak torques for involved and uninvolved limbs were recorded. The quadriceps and hamstring strength indexes were calculated by the torque produced by the involved limb divided by the torque produced by the uninvolved limb, which were then expressed as a percentage.

\subsubsection{Functional performance}

One leg hop distance test (OLHT) and Star Excursion Balance Test (SEBT) were used to assess the functional performance.

For the OLHT, the participants stood on one leg with toes behind a mark on the floor. They were instructed to jump as far as possible with a controlled landing. The test was performed until three successful jumps were performed for each leg. The tests were performed with the uninvolved limb first and then the involved limb. The distance was measured in centimeters and the average of the three trials was recorded.

The anterior (ANT), posteromedial (PM) and posterolateral (PL) directions of the SEBT were used to assess dynamic balance [31]. Participants were instructed to stand in the middle of the grid with tapelines extending out $100 \mathrm{~cm}$. The angle between ANT and PM or PL directions was set at $135^{\circ}$, and between PM and PL was set at $90^{\circ}$. The participants were instructed to reach as far as possible along each of the three lines, make a light toe-touch on the line without shifting weight, and return to the center of the grid while maintaining single-leg balance. Measurements were taken from the most distal aspect of the toes. Three practice trials were given for each limb for each direction. The participants then performed three trials in the three directions for each limb. The average of the three reach distances was recorded.

LSI was calculated for each test by dividing injured limb scores by uninjured limb scores, expressed as a percentage.

\subsubsection{Subjective knee scoring}

GRS score was only used for involved limb after the participants finished the overall physical performance tests for each condition (no intervention, KT and $\mathrm{KB}$ ). The patients were asked to rate their perceived level of knee performance compared with their uninvolved limb, on a scale of 100 points with a higher score showing a better outcome [32].

The International Knee Document Committee 2000 Subjective Knee Form (IKDC) and TSK-17 scores were collected once at six months after ACLR before all testing conditions. IKDC contains 10 items related to knee symptoms, daily and sports activities. Scores range from 0 to 100 , higher scores indicate less disability [33]. TSK-17 includes 17 items, with scores ranging from 17 to 68 points, with higher scores indicating a greater degree of kinesiophobia. Vlaeyen et al. [28] developed a cutoff score where TSK-17 score $\geq 37$ is considered as a high score for patients with back pain.

\subsection{Statistical analysis}

SPSS 22.0 (SPSS Inc., Chicago, IL) was used for statistical analysis. Descriptive statistics were generated for demographic data including: age, height, body mass and BMI. In addition, pre-injury Tegner scores, knee strength, functional performance tests and patient-reported outcomes were expressed as means (M) and standard deviations (SD). A repeated measures ANOVA, was used to determine the differences between the three conditions (no intervention, KT and KB) with a post hoc pairwise comparison tests with a Bonferroni correction. Effect sizes (ES) for the pairwise comparisons were computed using Cohen's d. ES was 
Table 1

Patient-reported outcomes at six months after ACLR, and GRS scores for all-time points.

\begin{tabular}{|c|c|c|c|c|c|c|}
\hline Patient-reported outcomes & IKDC & Lysholm & Tampa & GRS_Bare & GRS_KT & GRS_KB \\
\hline $\mathrm{n}=30,($ mean $\pm S D)$ & $87.0 \pm 13.3$ & $94.7 \pm 5.9$ & $40.8 \pm 3.6$ & $67.3 \pm 10.8$ & $78.0 \pm 10.3$ & $83.7 \pm 12.2$ \\
\hline
\end{tabular}

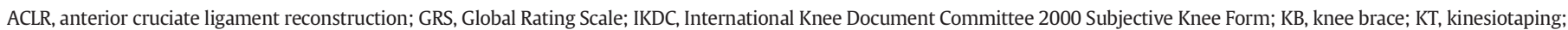
$\mathrm{SD}$, standard deviation.

interpreted as small, medium and large based on ES values of 0.2, 0.5, and 0.8 respectively. Significance level was set at $P<0.05$.

\section{Results}

The patients' reported outcomes are shown in Table 1 and the functional performance outcomes at all-time points are shown in Table 2 .

There were no significant differences between the test conditions for the uninvolved limb in SEBT. Analysis from the involved limb showed a number of differences. SEBT_PM showed a significant difference in reach distance between the conditions $\left(F_{(2,58)}=5.14\right.$, $P=0.01)$. The pairwise comparisons showed a significant difference between no intervention and both $\mathrm{KT}$ and $\mathrm{KB}$, with $\mathrm{KT}$ and $\mathrm{KB}$ increasing the reach distance $(P=0.01$, ES: 0.62) and ( $P=0.04, \mathrm{ES}: 0.47)$, respectively. A significant difference was also observed between the conditions in SEBT_PL reach distance $\left(\mathrm{F}_{(2,58)}=4.53, P=0.01\right)$. The pairwise comparisons showed that KB reduced SEBT_PL reach distance when compared with KT $(P=0.02$, ES: 0.54$)$. There was no significant difference between the conditions in SEBT_ANT reach distance $\left(\mathrm{F}_{(2,58)}=0.27, P=0.76\right)$.

There were no significant differences between the test conditions for the uninvolved limb in OLHT. Analysis from the involved limbs showed that there was a significant difference between the conditions $\left(\mathrm{F}_{(2,58)}=7.04, P=0.002\right)$. The pairwise comparisons showed that both KT and KB increased the hop distance compared with no intervention (KT: $P=0.01, \mathrm{ES}: 0.56, \mathrm{~KB}: P=0.04$, ES: 0.48 ), respectively.

There was a significant difference in quadriceps strength between the test conditions at $180^{\circ} / \mathrm{s}\left(\mathrm{F}_{(2,58)}=6.52, P=0.003\right)$ and $60^{\circ} / \mathrm{s}\left(\mathrm{F}_{(2,58)}=4.09, P=0.02\right)$. The pairwise comparisons showed that the KB increased quadriceps strength at both $180^{\circ} / \mathrm{s}(P=0.002$, ES: 0.53$)$ and $60^{\circ} / \mathrm{s}(P=0.04$, ES: 0.45$)$ compared with no intervention. No difference was observed between no intervention and KT in quadriceps strength at $180^{\circ} / \mathrm{s}$ or $60^{\circ} / \mathrm{s}(P=0.7)$ and $(P=1.00)$, respectively. There was a significant difference between the test conditions in hamstring strength at $180^{\circ} / \mathrm{s}\left(\mathrm{F}_{(2.58)}=3.99, P=0.02\right)$ and $60^{\circ} / \mathrm{s}\left(\mathrm{F}_{(2,58)}=5.49, P=0.01\right)$. As with the quadriceps, the pairwise comparisons

Table 2

ANOVA and pairwise comparisons between the conditions.

\begin{tabular}{|c|c|c|c|c|}
\hline Performance tests & $\begin{array}{l}\text { No intervention } \\
\text { (mean } \pm \text { SD) }\end{array}$ & $\begin{array}{l}\text { Kinesiotaping } \\
(\text { mean } \pm \mathrm{SD})\end{array}$ & $\begin{array}{l}\text { Knee brace } \\
(\text { mean } \pm S D)\end{array}$ & $P$-value \\
\hline OLHT INV $(\mathrm{cm})$ & $144.9 \pm 33.6$ & $153.1 \pm 34.6^{*}$ & $152.8 \pm 35.0^{*}$ & 0.002 \\
\hline OLHT UINV $(\mathrm{cm})$ & $161.9 \pm 28.6$ & $164.5 \pm 27.6$ & $164.3 \pm 29.7$ & 0.61 \\
\hline OLHT LSI (\%) & $88.8 \pm 11.0$ & $91.8 \pm 10.8$ & $91.8 \pm 10.3$ & 0.08 \\
\hline SEBT_ANT INV $(\mathrm{cm})$ & $68.9 \pm 6.8$ & $69.1 \pm 5.9$ & $69.4 \pm 5.8$ & 0.76 \\
\hline SEBT_ANT UINV (cm) & $70.8 \pm 5.9$ & $71.1 \pm 5.2$ & $71.8 \pm 5.6$ & 0.30 \\
\hline SEBT_ANT LSI (\%) & $96.7 \pm 5.3$ & $97.4 \pm 3.4$ & $96.7 \pm 4.3$ & 0.65 \\
\hline SEBT_PM INV $(\mathrm{cm})$ & $91.4 \pm 9.9$ & $94.9 \pm 8.2^{*}$ & $94.5 \pm 10.2^{*}$ & 0.009 \\
\hline SEBT_PM UINV $(\mathrm{cm})$ & $94.6 \pm 9.7$ & $96.8 \pm 8.3$ & $97.2 \pm 7.8$ & 0.13 \\
\hline SEBT_PM LSI (\%) & $97.0 \pm 5.7$ & $99.1 \pm 4.5$ & $98.1 \pm 4.9$ & 0.23 \\
\hline SEBT_PL INV (cm) & $92.9 \pm 2.1$ & $95.0 \pm 1.8^{\dagger}$ & $91.8 \pm 1.8^{\dagger}$ & 0.01 \\
\hline SEBT_PL UINV $(\mathrm{cm})$ & $94.1 \pm 10.0$ & $96.1 \pm 9.8$ & $93.7 \pm 8.6$ & 0.16 \\
\hline SEBT_PL LSI (\%) & $99.2 \pm 5.3$ & $99.5 \pm 4.2$ & $98.2 \pm 4.7$ & 0.49 \\
\hline $\mathrm{H}$ INV $180^{\circ} / \mathrm{s}(\mathrm{Nm} / \mathrm{kg})$ & $1.44 \pm 0.3$ & $1.51 \pm 0.4$ & $1.53 \pm 0.4^{*}$ & 0.02 \\
\hline H UINV $180^{\circ} / \mathrm{s}(\mathrm{Nm} / \mathrm{kg})$ & $1.48 \pm 0.3$ & $1.53 \pm 0.3$ & $1.15 \pm 0.3$ & 0.34 \\
\hline $\mathrm{HI} 180^{\circ} / \mathrm{s}(\%)$ & $97.0 \pm 11.7$ & $98.2 \pm 15.4$ & $101.2 \pm 15.5$ & 0.25 \\
\hline $\mathrm{H}$ INV $60^{\circ} / \mathrm{s}(\mathrm{Nm} / \mathrm{kg})$ & $1.74 \pm 0.4$ & $1.70 \pm 0.3$ & $1.82 \pm 0.5^{*}$ & 0.007 \\
\hline H UINV $60^{\circ} / \mathrm{s}(\mathrm{Nm} / \mathrm{kg})$ & $1.79 \pm 0.3$ & $1.84 \pm 0.3$ & $1.78 \pm 0.3$ & 0.19 \\
\hline $\mathrm{HI} 60^{\circ} / \mathrm{s}(\%)$ & $96.9 \pm 15.5$ & $92.3 \pm 11.6$ & $102.1 \pm 15.5^{*}$ & $<\mathbf{0 . 0 0 1}$ \\
\hline Q INV $180^{\circ} / \mathrm{s}(\mathrm{Nm} / \mathrm{kg})$ & $1.66 \pm 0.5$ & $1.72 \pm 0.5$ & $1.82 \pm 0.5^{*}$ & 0.003 \\
\hline Q UINV $180^{\circ} / \mathrm{s}(\mathrm{Nm} / \mathrm{kg})$ & $2.04 \pm 0.3$ & $2.12 \pm 0.4$ & $2.08 \pm 0.3$ & 0.19 \\
\hline QI $180^{\circ} / \mathrm{s}(\%)$ & $80.9 \pm 17.4$ & $85.3 \pm 20.1$ & $86.4 \pm 13.4$ & 0.11 \\
\hline QT INV $60^{\circ} / \mathrm{s}(\mathrm{Nm} / \mathrm{kg})$ & $2.20 \pm 0.8$ & $2.21 \pm 0.7$ & $2.33 \pm 0.7^{*}$ & 0.02 \\
\hline Q UINV $60^{\circ} / \mathrm{s}(\mathrm{Nm} / \mathrm{kg})$ & $2.70 \pm 0.5$ & $2.70 \pm 0.5$ & $2.60 \pm 0.5$ & 0.18 \\
\hline QI 60\% $/ \mathrm{s}(\%)$ & $78.6 \pm 16.9$ & $80.1 \pm 14.5$ & $87.7 \pm 17.5^{*}$ & 0.001 \\
\hline
\end{tabular}

ANOVA, analysis of variance; ANT anterior; $\mathrm{H}$, hamstring; $\mathrm{HI}$ and $\mathrm{QI}$, ratio of involved to uninvolved side for hamstrings and quadriceps, respectively; INV, involved; LSI, Limb Symmetry Index; OLHT, one leg hop test; PL, posterolateral; PM, posteromedial; $\mathrm{Q}$ quadriceps; SEBT, Star excursion balance test; UINV, uninvolved.

* Data indicate significant difference from pairwise comparisons between kinesiotaping or knee brace with no intervation $(\mathrm{P}<0.05)$.

$\uparrow$ Data indicate significant difference from pairwise comparisons between kinesiotaping and knee brace $(\mathrm{P}<0.05)$. showed that the KB increased hamstring strength compared with no intervention at both $180^{\circ} / \mathrm{s}(P=0.03$, ES: 0.47$)$ and $60^{\circ} / \mathrm{s}(P=0.04$, ES: 0.47$)$. No difference was observed between no intervention and KT in hamstring strength at $180^{\circ} / \mathrm{s}(P=0.85)$ and $60^{\circ} / \mathrm{s}$ $(P=0.84)$.

The GRS score was found to be significantly different between the different conditions $\left(\mathrm{F}_{(2,58)}=45.19, P<0.001\right)$. The pairwise comparisons showed that individuals reported better knee function with $\mathrm{KB}$ when compared with no intervention and $\mathrm{KT}(P<0.001$, ES: 1.64) and ( $P=0.03$, ES: 0.49$)$, respectively, and they also reported better knee function with KT compared with no intervention $(P<0.001$, ES: 1.68).

\section{Discussion}

The main objective of this study was to investigate the effects of a prophylactic KB and the application of KT on functional performance in individuals six months after ACL reconstruction who desired to return to their pre-injury activity level, but could not due to higher levels of kinesiophobia. We observed that both KB and KT improved the balance and hop performance, and also the patient-reported knee function, but only KB was found to increase the quadriceps and hamstring peak torques. Therefore, our findings supported the hypothesis that external supports improved the functional performance in ACLR individuals with higher kinesiophobia levels.

Although the participants of this study almost passed the RTS criteria at six months after surgery, their lower self-reported knee function levels and higher kinesiophobia scores supported that psychological recovery and physical recovery did not occur simultaneously [4]. Hartigan et al. [16] demonstrated that large decreases in kinesiophobia level scores were observed from pre-surgery to six months after surgery, but the kinesiophobia levels were still high at six months when the patients are typically returning to sports. In addition, higher kinesiophobia scores were found associated with lower self-reported knee function levels and a lower return to sport rate [14,34], but no relationship was found between kinesiophobia levels and the quadriceps strength and hop performance [35]. Therefore, the lower ratio of peak torque between the involved and uninvolved sides for quadriceps in this study might not be due to higher kinesiophobia levels. Everhart et al. [15] suggested that the ACLR individuals must be willing to overcome the kinesiophobia to return to their pre-injury level of activity and sports. Therefore, the use of bracing and taping could be an option for ACLR individuals to overcome kinesiophobia during the RTS phase of their rehabilitation.

LSI for hamstring strength, balance and hop performance (>85\%) and IKDC scores (>86.2) [10] met the RTS criteria; however the quadriceps did not meet previously published RTS criteria $[10,12]$. Thomeé et al. [36] reported that only $25 \%$ of patients had reached an LSI value of $\geq 85 \%$ for the knee extensors at six months after ACLR. Although the recovery of quadriceps strength is an important outcome following ACL reconstruction and decision for RTS, quadriceps strength deficits have been found as high as 39\% at six months after ACLR [37].

In this study, quadriceps strength deficit was around $20 \%$ and which was improved with the KB to a $12.3 \%$ deficit. Previous studies reported that knee strength outcomes did not change with $\mathrm{KB}$ and also some studies showed that quadriceps strength decreased with KB [22,24, 38]. Acierno et al. [38] showed that KBs did not alter muscle activity in asymptomatic individuals and they also observed a slight decrease in their quadriceps muscle torque. However, previous studies have not focused on the individuals with higher kinesiophobia levels. In the present study, it was hypothesized that the compressive force of the brace might improve the individual's confidence in their knee and allow the 
individuals to exert higher peak muscle torques. The one leg hop for distance has been shown to be one of the strongest predictive parameters for assessing RTS [39]. Although the participants passed OLHT criteria, we found that both KT and KB enhanced the LSI for OLHT. Contrary to our findings, KT and KB were shown not to improve the hop performance in healthy individuals $[38,40]$ and in ACLR individuals at one year after surgery [24]. We postulate that these improvements in OLHT could be mostly due to psychological supports by KT and KB which may help the participants to have greater confidence in their knee while hopping which, in turn, may reduce their kinesiophobia.

There is some evidence that supports KB enhancing the single limb balance $[17,18]$ but KT has no effect on balance in ACLR individuals [27]. Wu et al. [18] found that KB enhanced the single limb standing balance at more than five months after ACLR. They concluded that the mechanical hinges of the brace were not an essential component for improving the balance. The improvements could have been due to the cutaneous stimulation of the skin, which is supported by Selfe et al. [41,42] who found significant improvements in coronal and transverse plane knee movements during step descent in normal subjects and patients with knee pain when wearing tape and a soft brace with no hinge. This current study found that both KT and KB increased SEBT_PM reach distance, but KB reduced posterolateral reach distance while KT increased it. This may be due to the KB limiting the knee flexion which might, in turn, decrease the posterolateral reach distance.

GRS scores of the participants with no intervention demonstrated that they were not satisfied with their knee function during the tests. Lower GRS scores could also support the findings of Logerstedt et al. [10] in which higher TSK scores were correlated with worse selfreported outcomes. Reporting better knee functions with KT and KB strengthen the argument that KB and KT could give psychological support to ACLR individuals, thus allowing greater confidence, strength and functional performance. In addition, as the KB gave more support than KT this could explain why the participants' GRS scores were higher with KB than KT.

The main adverse effect of interventions such as bracing and taping is that patients sometimes do not discontinue to use them or they become over-reliant on them during activities and/or sports. Before suggesting bracing and taping, patients should be informed that the use of external supports may be used to assist in overcoming kinesiophobia in the short term; however the effects of long-term use are unknown and cannot be advised clinically without more evidence.

There were some limitations of the study. First, the participants of the study were mostly recreationally active individuals, and thus the external supports might not be as effective for professional athletes. Second, we only included individuals who had primary ACL reconstruction. Our results may not apply for ACLR individuals who had ACLR with meniscus and/or cartilage repair.

\section{Conclusion}

Prophylactic KB and KT applications could be a useful option to assist ACLR individuals in overcoming kinesiophobia during return to preinjury activity level and/or sport. When compared with KT, KBs appeared to be more effective at enhancing knee strength and selfreported knee function. Future studies are needed to investigate the longer-term effects of such interventions to overcome kinesiophobia in ACLR individuals and to determine the longevity of these effects.

\section{Conflicts of interest}

The authors declare no conflicts of interest.

\section{References}

[1] Clayton RA, Court-Brown CM. The epidemiology of musculoskeletal tendinosus and ligamentous injuries. Injury 2008;39(12):1338-44.
[2] Majewski M, Susanne H, Klaus S. Epidemiology of athletic knee injuries: a 10-year study. Knee 2006;13(3):184-8.

[3] Beynnon BD, Johnson RJ, Abate JA, Fleming BC, Nichols CE. Treatment of anterior cruciate ligament injuries, part I. Am J Sports Med 2005;33(10):1579-602.

[4] Ardern CL, Webster KE, Taylor NF, Feller JA. Return to sport following anterior cruciate ligament reconstruction surgery: a systematic review and meta-analysis of the state of play. Br J Sports Med 2011;45(7):596-606.

[5] Hartigan EH, Axe MJ, Snyder-Mackler L. Time line for noncopers to pass return-tosports criteria after anterior cruciate ligament reconstruction. J Orthop Sports Phys Ther 2010;40(3):141-54.

[6] Ardern CL, Taylor NF, Feller JA, Webster KE. Fifty-five per cent return to competitive sport following anterior cruciate ligament reconstruction surgery: an updated systematic review and meta-analysis including aspects of physical functioning and contextual factors. Br J Sports Med 2014;48(21):1543-52.

[7] Fitzgerald GK, Axe MJ, Snyder-Mackler L. A decision-making scheme for returning patients to high-level activity with nonoperative treatment after anterior cruciate ligament rupture. Knee Surg Sports Traumatol Arthrosc 2000;8(2):76-82.

[8] Neeter C, Gustavsson A, Thomee P, Augustsson J, Thomee R, Karlsson J. Development of a strength test battery for evaluating leg muscle power after anterior cruciate ligament injury and reconstruction. Knee Surg Sports Traumatol Arthrosc 2006; 14(6):571-80.

[9] Hopper DM, Goh SC, Wentworth LA, Chan DY, Chau JH, Wootton GJ, et al. Test-retest reliability of knee rating scales and functional hop tests one year following anterior cruciate ligament reconstruction. Phys Ther Sport 2002;3(1):10-8.

[10] Logerstedt D, Di Stasi S, Grindem H, Lynch A, Eitzen I, Engebretsen L, et al. Selfreported knee function can identify athletes who fail return-to-activity criteria up to 1 year after anterior cruciate ligament reconstruction: a Delaware-Oslo ACL cohort study. J Orthop Sports Phys Ther 2014;44(12):914-23.

[11] Barber-Westin SD, Noyes FR. Factors used to determine return to unrestricted sports activities after anterior cruciate ligament reconstruction. Arthroscopy 2011;27(12): 1697-705.

[12] van Grinsven S, van Cingel RE, Holla CJ, van Loon CJ. Evidence-based rehabilitation following anterior cruciate ligament reconstruction. Knee Surg Sports Traumatol Arthrosc 2010;18(8):1128-44.

[13] Ardern CL, Taylor NF, Feller JA, Whitehead TS, Webster KE. Psychological responses matter in returning to preinjury level of sport after anterior cruciate ligament reconstruction surgery. Am J Sports Med 2013;41(7):1549-58.

[14] Kvist J, Ek A, Sporrstedt K, Good L. Fear of re-injury: a hindrance for returning to sports after anterior cruciate ligament reconstruction. Knee Surg Sports Traumatol Arthrosc 2005;13(5):393-7.

[15] Everhart JS, Best TM, Flanigan DC. Psychological predictors of anterior cruciate ligament reconstruction outcomes: a systematic review. Knee Surg Sports Traumatol Arthrosc 2015;23(3):752-62.

[16] Hartigan EH, Lynch AD, Logerstedt DS, Chmielewski TL, Snyder-Mackler L. Kinesiophobia after anterior cruciate ligament rupture and reconstruction: noncopers versus potential copers. J Orthop Sports Phys Ther 2013;43(11):821-32.

[17] Birmingham TB, Kramer JF, Kirkley A, Inglis JT, Spaulding SJ, Vandervoort AA. Knee bracing after ACL reconstruction: effects on postural control and proprioception. Med Sci Sports Exerc 2001;33(8):1253-8.

[18] Wu GK, Ng GY, Mak AF. Effects of knee bracing on the sensorimotor function of subjects with anterior cruciate ligament reconstruction. Am J Sports Med 2001;29(5): 641-5.

[19] Risberg MA, Holm I, Steen H, Eriksson J, Ekeland A. The effect of knee bracing after anterior cruciate ligament reconstruction. A prospective, randomized study with two years' follow-up. Am J Sports Med 1999;27(1):76-83.

[20] Birmingham TB, Bryant DM, Giffin JR, Litchfield RB, Kramer JF, Donner A, et al. A randomized controlled trial comparing the effectiveness of functional knee brace and neoprene sleeve use after anterior cruciate ligament reconstruction. Am J Sports Med 2008;36(4):648-55.

[21] Brandsson S, Faxen E, Kartus J, Eriksson BI, Karlsson J. Is a knee brace advantageous after anterior cruciate ligament surgery? A prospective, randomised study with a two-year follow-up. Scand J Med Sci Sports 2001;11(2):110-4.

[22] Paluska SA, McKeag DB. Knee braces: current evidence and clinical recommendations for their use. Am Fam Physician 2000;61(2):411-8 [423-414].

[23] Marx RG, Jones EC, Angel M, Wickiewicz TL, Warren RF. Beliefs and attitudes of members of the American Academy of Orthopaedic surgeons regarding the treatment of anterior cruciate ligament injury. Arthroscopy 2003;19(7):762-70.

[24] Goodstadt NM, Hunter-Giordano A, Axe MJ, Snyder-Mackler L. Functional testing to determine readiness to discontinue brace use, one year after ACL reconstruction. Int J Sports Phys Ther 2013;8(2):91-6.

[25] Kase K, Hashimoto T, Okane T. Kinesio taping perfect manual: amazing taping therapy to eliminate pain and muscle disorders. Albuquerque, NM: KMS, LLC; 1996.

[26] Slupik A, Dwornik M, Bialoszewski D, Zych E. Effect of kinesio taping on bioelectrical activity of vastus medialis muscle. Prelim Rep Ortop Traumatol Rehabil 2007;9(6): 644-51.

[27] Oliveira AK, Borges DT, Lins CA, Cavalcanti RL, Macedo LB, Brasileiro JS. Immediate effects of kinesio taping on neuromuscular performance of quadriceps and balance in individuals submitted to anterior cruciate ligament reconstruction: a randomized clinical trial. J Sci Med Sport 2016;19(1):2-6.

[28] Vlaeyen JW, Kole-Snijders AM, Boeren RG, van Eek H. Fear of movement/(re)injury in chronic low back pain and its relation to behavioral performance. Pain 1995; 62(3):363-72.

[29] Baltaci G, Aktas G, Camci E, Oksuz S, Yildiz S, Kalaycioglu T. The effect of prophylactic knee bracing on performance: balance, proprioception, coordination, and muscular power. Knee Surg Sports Traumatol Arthrosc 2011;19(10):1722-8. 
[30] Aktas G, Baltaci G. Does kinesiotaping increase knee muscles strength and functional performance? Isokinet Exerc Sci 2011;19(3):149.

[31] Gribble PA, Hertel J, Plisky P. Using the star excursion balance test to assess dynamic postural-control deficits and outcomes in lower extremity injury: a literature and systematic review. J Athl Train 2012;47(3):339-57.

[32] Irrgang JJ, Snyder-Mackler L, Wainner RS, Fu FH, Harner CD. Development of a patient-reported measure of function of the knee. J Bone Joint Surg Am 1998; $80(8): 1132-45$

[33] Irrgang JJ, Anderson AF, Boland AL, Harner CD, Kurosaka M, Neyret P, et al. Development and validation of the international knee documentation committee subjective knee form. Am J Sports Med 2001;29(5):600-13.

[34] Lentz TA, Zeppieri Jr G, Tillman SM, Indelicato PA, Moser MW, George SZ, et al. Return to preinjury sports participation following anterior cruciate ligament reconstruction: contributions of demographic, knee impairment, and self-report measures. J Orthop Sports Phys Ther 2012;42(11):893-901.

[35] Lentz TA, Tillman SM, Indelicato PA, Moser MW, George SZ, Chmielewski TL. Factors associated with function after anterior cruciate ligament reconstruction. Sports Health 2009;1(1):47-53.

[36] Thomee R, Kaplan Y, Kvist J, Myklebust G, Risberg MA, Theisen D, et al. Muscle strength and hop performance criteria prior to return to sports after ACL reconstruction. Knee Surg Sports Traumatol Arthrosc 2011;19(11):1798-805.
[37] Thomas AC, Villwock M, Wojtys EM, Palmieri-Smith RM. Lower extremity muscle strength after anterior cruciate ligament injury and reconstruction. J Athl Train 2013;48(5):610-20.

[38] Acierno SP, D'Ambrosia C, Solomonow M, Baratta RV, D'Ambrosia RD. Electromyography and biomechanics of a dynamic knee brace for anterior cruciate ligament deficiency. Orthopedics 1995;18(11):1101-7.

[39] Muller U, Kruger-Franke M, Schmidt M, Rosemeyer B. Predictive parameters for return to pre-injury level of sport 6 months following anterior cruciate ligament reconstruction surgery. Knee Surg Sports Traumatol Arthrosc 2015;23(12):3623-31.

[40] Lins CAD, Neto FL, de Amorim ABC, Macedo LD, Brasileiro JS. Kinesio taping (R) does not alter neuromuscular performance of femoral quadriceps or lower limb function in healthy subjects: randomized, blind, controlled, clinical trial. Manual Ther 2013; 18(1):41-5.

[41] Selfe J, Richards J, Thewlis D, Kilmurray S. The biomechanics of step descent under different treatment modalities used in patellofemoral pain. Gait Posture 2008; 27(2):258-63.

[42] Selfe J, Thewlis D, Hill S, Whitaker J, Sutton C, Richards J. A clinical study of the biomechanics of step descent using different treatment modalities for patellofemora pain. Gait Posture 2011;34(1):92-6. 